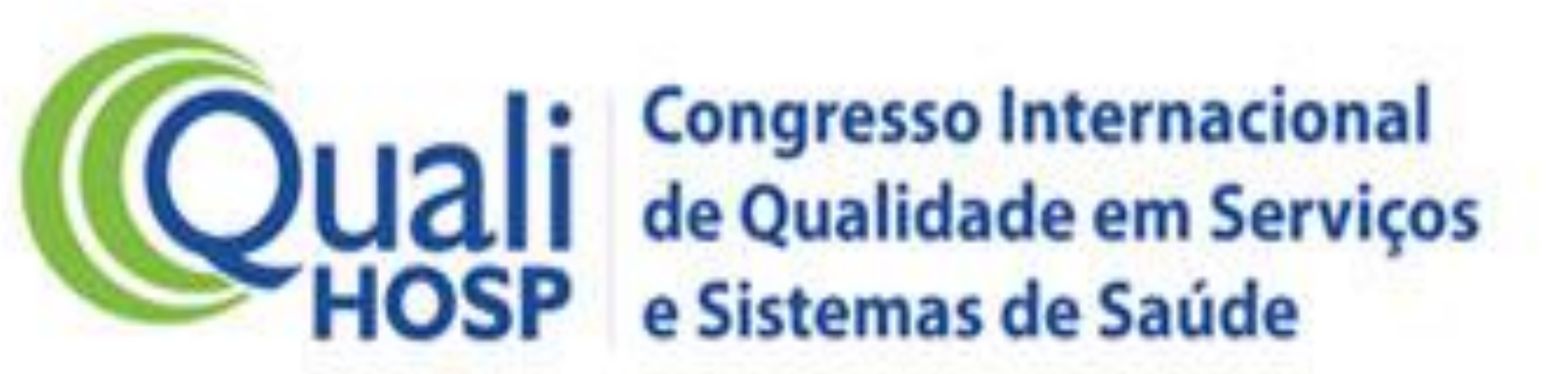

LFV EAESP

MORITSUGU, Marlene Uehara; Silveira, Ana Stella de Azevedo; Speierl, Hannelore; Rovari, Fabiana Yassuko

\title{
PROGRAMA DE CAPACITAÇÃO EM MANEJO DE AGITAÇÃO PSICOMOTORA E TÉCNICA DE CONTENCÃO MECÂNICA. \\ ENSINO
}

Introdução: A agitação psicomotora está entre as situações de emergências psiquiátricas mais comuns. Seu manejo exige conhecimento teórico e habilidade técnica, pois a evolução desta situação pode oferecer risco para os pacientes e respalda os colaboradores envolvidos. Após abordagem verbal e tentativa de controlar o quadro com medicação, é possível que a equipe tenha que realizar a contenção mecânica, técnica utilizada para restringir os movimentos do paciente agressivo ou agitado no leito, limitando sua habilidade de movimento em caso de riscos para si mesmo ou aos outros, através do uso de dispositivos como faixas de contenção nos quatro membros (1).

Objetivo: Descrever o impacto do projeto interinstitucional de capacitação em manejo de agitação psicomotora e técnica de contenção física e mecânica.

Método: Trata-se de um relato de experiência realizado em sete unidades de tratamento em Saúde Mental em São Paulo, incluindo serviços ambulatoriais, comunitários (CAPS) e hospitalares geridos por uma organização social de saúde. Foi ministrada aula expositiva e realizada simulação realística pela enfermeira de educação continuada para demonstração da postura corporal, forma de imobilização e movimentação correta dos participantes durante a contenção visando proteção e redução do risco de acidentes com o paciente e membros da equipe. Foram aplicados pré e pós-testes para 290 pessoas no período de um mês. O questionário consistia em 10 afirmações referentes ao tema, para as quais o colaborador responderia "verdadeiro? ou "falso".

Resultados: No pré-teste, foram preenchidas 2367 respostas e no pós-teste 2139 . No pré-teste, a porcentagem de acerto foi de $57,8 \%$ e no pós-teste foi de $68,1 \%$, demonstrando uma melhora de dez pontos percentuais.

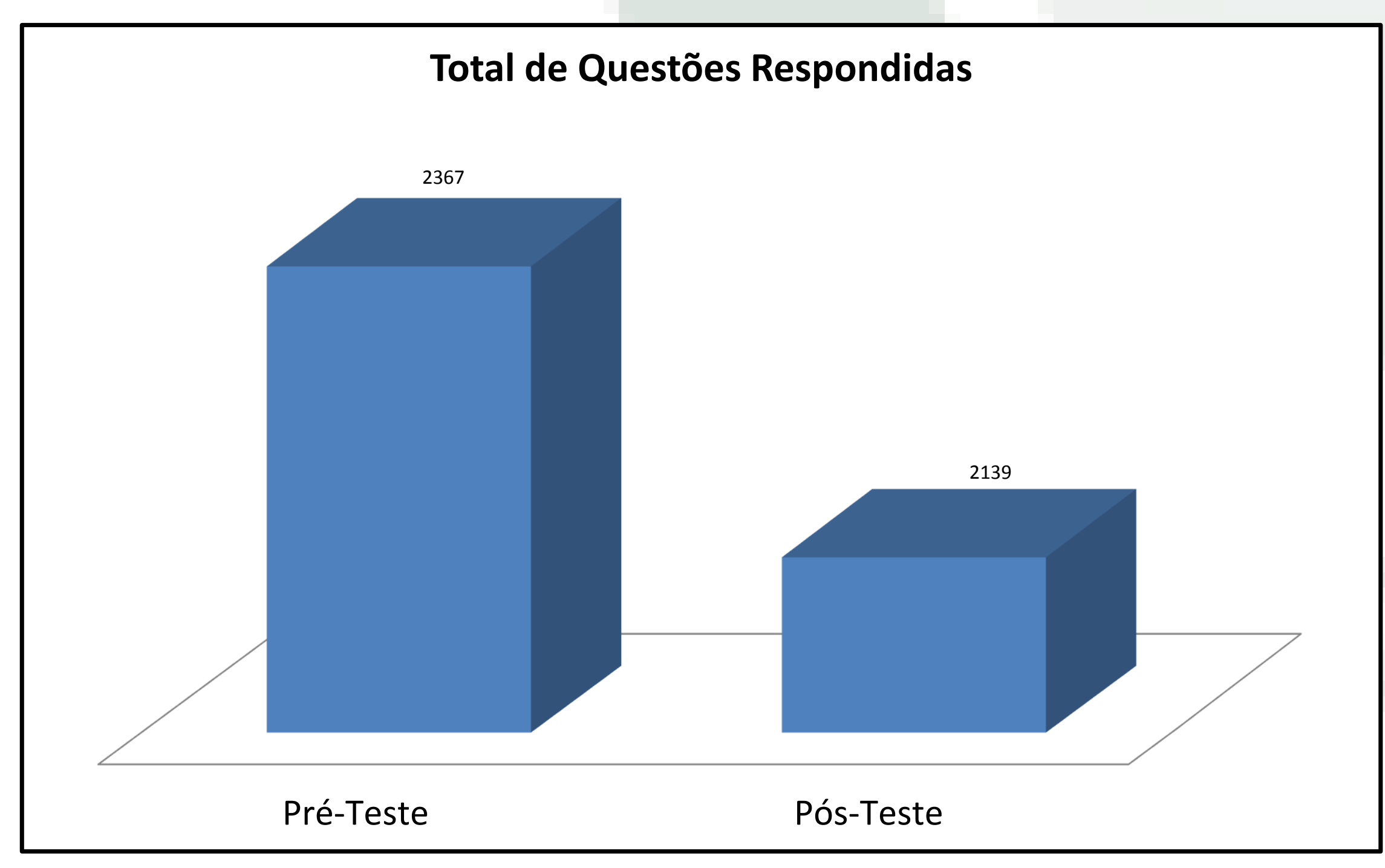

Fig.1. Total de questões respondidas nos pré e pós-testes

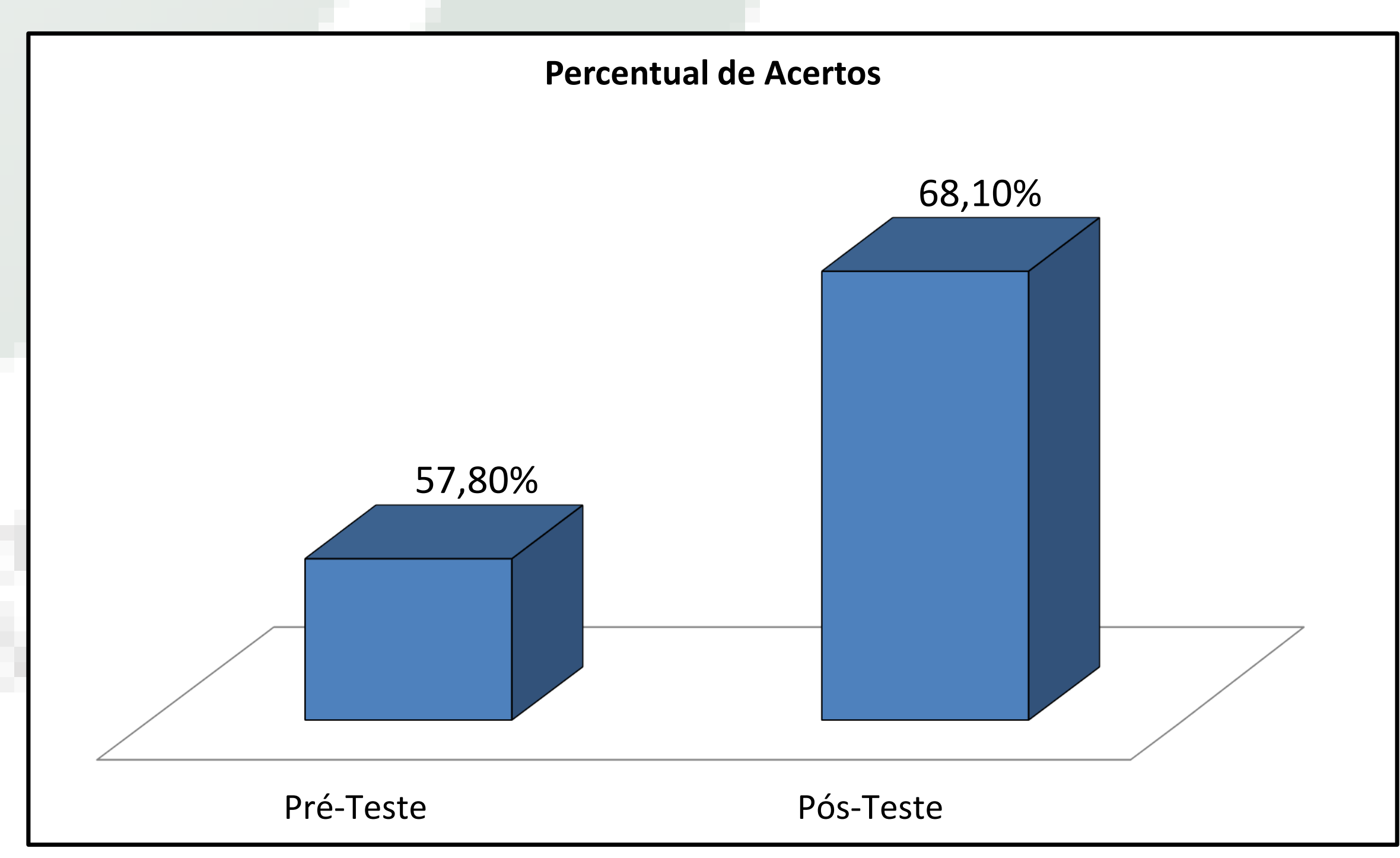

Fig.2. Percentual de questões com acerto nos pré e pós-testes

Conclusão: Foi evidenciado um impacto positivo no treinamento da equipe multiprofissional, bem como a importância da educação permanente, uma vez que apesar de contar com equipe formada por profissionais especializados em saúde mental, havia desconhecimento relacionado à técnica de contenção física e mecânica antes da capacitação. 